\title{
O Potencial Gerador de Crescimento, Renda e Emprego do Turismo no Distrito Federal - Brasil
}

\author{
The Potencial for Economics Growth, Income, and Employment Generation by Tourism in \\ Distrito Federal - Brazil
}

\section{El Potencial Generador de Crecimiento, Renta y Empleo del Turismo en el Distrito Federal - Brasil}

Milene Takasago ${ }^{1}$

Maria de Lourdes Rollemberg Mollo²

\begin{abstract}
Resumo
Este artigo examina o potencial de estímulo ao crescimento da produção e de geração de renda e emprego que tem o turismo no Distrito Federal. Para tanto, utiliza informações contidas na matriz de insumo-produto regionalizada estimada pelo CET-UnB, tirando conclusões dentro de uma ótica de desenvolvimento econômico setorial e regional. São destacadas, inicialmente, algumas conclusões da chamada estratégia de desenvolvimento desequilibrado proposta por Hirshman (1961), que explora exatamente o potencial de desenvolvimento setorial a partir de estímulos a setores específicos. Essas conclusões norteiam a descrição e a análise da matriz de insumo-produto do DF, destacando seu potencial analítico para efeito de planejamento de políticas públicas. Os resultados obtidos sobre os potenciais de geração de produção, emprego e renda no Distrito Federal, a partir do crescimento do turismo, são analisados por setor componente do turismo e em relação ao potencial médio de geração de emprego, renda e produção da economia do DF como um todo. Palavras-chave: desenvolvimento; matriz de insumo-produto; turismo.
\end{abstract}

\begin{abstract}
This paper examines the potential of tourism to stimulate growth of production and generation of income and employment in the Distrito Federal. It uses information from the regionalized Input-Ouptut Matrix, which was computed by the CET-UnB, drawing conclusions from a sectional and regional economic development perspective. Initially, it is stressed some conclusions from the so called strategy of disequilibrated development, as proposed by Hirshman (1961), which explores the potential for sectional development
\end{abstract}

\footnotetext{
${ }^{1}$ Pesquisadora do Núcleo de Estudos em Economia do Turismo. Possui graduação em Matemática pela Universidade Federal de Viçosa (1992), mestrado em Matemática pela Universidade de Brasília (1994) e doutorado em Economia pela Universidade de Brasília (2006). Atualmente é professora adjunta no Departamento de Economia na Universidade de Brasília. E-mail: mtakasago@uol.com.br.

${ }^{2}$ Coordenadora do Núcleo de Estudos em Economia do Turismo. Bolsista de Produtividade em Pesquisa do CNPq - Nível 1B. Possui graduação em Economia pela Universidade de Brasília (1973), mestrado em Economia pela Universidade de Brasília (1977) e doutorado em Monnaie, Finance et Banques - Université de Paris X, Nanterre (1989). É professora titular da Universidade de Brasília, atuando no Departamento de Economia e no Centro de Excelência em Turismo - CET. E-mail: mlmollo@unb.br.
} 
departing from stimulus to specific sectors. Those conclusions direct the description and analysis of the regional Input-Ouptut Matrix, stressing its application to the planning of public policies. The results related to generation of output, employment, and income in the Distrito Federal, due to the increasing in tourism, are analyzed by the sector component of tourism in relation to the average generation of employment, income, and output for the economy of the Distrito Federal as a whole.

Keywords: development; input-output matrix; tourism.

\section{Resumen}

Este artículo examina el potencial de estímulo en relación al crecimiento que la producción y la generación de renta y empleo tienen sobre el turismo en el Distrito Federal. Para ello, utiliza informaciones contenidas en la matriz de insumo- producto (input output) regionalizada, estimada por el CET-UnB, generando conclusiones dentro de una óptica de desenvolvimiento económico sectorial y regional. Inicialmente, destacan algunas conclusiones de la llamada estrategia de desenvolvimiento desequilibrado propuesta por Hirshman (1961), que explora exactamente el potencial de desenvolvimiento sectorial, a partir de estímulos a sectores específicos. Esas conclusiones orientan la descripción y el análisis de la matriz insumo-producto del DF, destacando su potencial analítico para efectos de planeamiento de políticas públicas. Los resultados obtenidos sobre los potenciales de generación de producción, empleo y renta en el Distrito Federal, a partir del crecimiento del turismo, son analizados por cada sector componente del turismo y en relación al potencial medio de generación de empleo, renta y producción de la economía del DF como un todo.

Palabras clave: desenvolvimient; matriz de insumo-producto; turismo

\section{Introdução}

O turismo, do ponto de vista econômico, é definido como um setor formado de parcelas de diferentes setores que servem ao turista, quais sejam transporte, alimentação, hospedagem, agências de viagem e cultura e lazer, na proporção em que atendem aos viajantes e não aos residentes. O turista, por sua vez, é definido como aquele cuja estadia no local analisado situase no intervalo de um dia a um ano. Assim, o setor de turismo envolve vários serviços e pode afetar positivamente ou negativamente os residentes.

Por um lado, ao disputar com os residentes os serviços e a infra-estrutura locais, por exemplo, os turistas podem contribuir negativamente para a localidade ou para os residentes, e assim também ocorre quando, ao consumir bens e serviços locais, dá origem ao aumento dos seus preços. Mas o turismo pode também beneficiar muito locais e regiões, quando, por exemplo, 
gera demanda para os produtos locais, quando estimula a produção e amplia as possibilidades de renda e emprego nas atividades de serviços que o constituem.

Este artigo busca examinar esse potencial de crescimento e geração de renda e emprego que tem o turismo no Distrito Federal. Para tanto utilizará informações contidas na matriz de insumo-produto regionalizada estimada pelo CET-UnB, tirando conclusões dentro de uma ótica de desenvolvimento econômico setorial e regional.

Para isso, no primeiro item serão destacadas brevemente algumas conclusões da chamada estratégia de desenvolvimento desequilibrado proposta por Hirshman (1961), que explora exatamente o potencial de desenvolvimento setorial a partir de estímulos a setores específicos, conclusões que nos ajudarão a organizar a análise dos resultados obtidos na matriz de insumoproduto. No item 2, a própria matriz e o seu potencial analítico são descritos, assim como serão mencionados alguns dos seus resultados agregados. Finalmente, no item 3, são analisados os potenciais geradores de produção, emprego e de renda dos vários setores que integram o turismo. Ao final, serão alinhadas algumas observações conclusivas, em particular no que se refere a recomendações de políticas públicas.

\section{Os Efeitos de Encadeamento do Processo de Crescimento e a Estratégia de Desenvolvimento Desequilibrado}

O turismo é uma atividade apontada como importante para ampliar os ganhos econômicos, em particular no caso do Distrito Federal, onde o setor de serviços predomina sobre os demais. A análise desses impactos positivos precisa ser realizada com cuidado, de forma a não apenas confirmar se existem ou não, como apreender quais as melhores maneiras de viabilizá-los ou estimulá-los, permitindo que sejam bem aproveitados os potenciais de geração de emprego e renda do setor.

Esse tipo de assunto é geralmente tratado em teorias ou estratégias de crescimento como a proposta por Rosenstein-Rodan (1969), que prescreve estímulos equilibrados entre os vários setores da economia, de forma que o crescimento de todos proporcione crescimento generalizado tanto de demanda quanto de oferta, ampliando o crescimento da economia como um todo. Esse tipo de proposta, porém, apresenta uma limitação importante, qual seja a de 
exigir recursos vultosos para estimular o crescimento econômico, tornando-se inexeqüível em regiões, locais e países com poucos recursos, justamente os mais necessitados de crescimento.

Essa situação, de resto mais freqüente e realista, é contornada pela chamada estratégia de crescimento desequilibrada, de autoria de Hirshman $(1957,1961)^{3}$. Segundo ele, o estímulo a apenas um ou alguns setores pode servir como indutor do crescimento dos demais. Isso porque o crescimento da produção dos primeiros aumenta a demanda por insumos e, assim, estimula o crescimento dos setores que os fornecem. Além disso, a produção em excesso de alguns setores estimulados inicialmente pode incentivar aumentos de produção de outros que utilizam esses primeiros setores como fornecedores de insumo para a cadeia produtiva dos últimos. Assim, o estímulo inicial amplia não apenas a produção dos setores que o receberam, mas também a de todos os que fornecem insumos para eles e os que demandam deles seus insumos. O crescimento maior de alguns setores do que de outros, por sua vez, leva a desequilíbrios que sinalizam ao mercado os lugares onde há escassez a ser sanada e mostram os pontos de estrangulamento a serem contornados pelas políticas públicas.

Referindo-se ao processo de industrialização, o próprio Hirshman (1989, p. 210-211) diz que:

Primeiro, uma operação industrial existente, dependendo inicialmente de importações não só para suas máquinas e equipamentos, mas também para muitos de seus insumos materiais, faria pressões para a fabricação doméstica desses insumos e por fim para uma indústria doméstica de bens de capital. Essa dinâmica foi chamada de encadeamentos para trás, já que a direção do estímulo para investimento adicional flui do artigo acabado para os materiais brutos ou semi processados dos quais ele é feito ou para as máquinas que ajudam a fazê-lo. Outro estímulo para investimento adicional aponta na outra direção e é, portanto, chamado de encadeamentos para frente: a existência de uma dada linha de produto A, que é um bem final ou é usado como um insumo na linha $\mathrm{B}$, age como um estimulante para o estabelecimento de outra linha $\mathrm{C}$, que também pode usar A como insumo.

Deve-se priorizar os investimentos nos setores onde há maiores efeitos de encadeamento, justamente para potencializar os benefícios deles para a economia como um todo. Segundo Lepenies (2009, p.76), no argumento original de Hirshman o desequilíbrio forçado, causado por crescimento desequilibrado era auto corretivo, devido à reação do mercado e em virtude de resposta das políticas públicas e tratava de estímulos a um único setor. Isso é relativizado

\footnotetext{
${ }^{3}$ Para uma visão mais geral das teorias do crescimento e do desenvolvimento econômico ver Souza (2009).
} 
mais tarde, quando ele percebe os limites da estratégia de crescimento desequilibrado que pode, por exemplo, dar margem a adiar certas tarefas em nome da idéia de "uma coisa por vez”. Diz então Hirshman (1961, p. 19) que:

o desenvolvimento não depende tanto de encontrar ótima confluência de certos recursos e fatores de produção, quanto de provocar e mobilizar, com propósito desenvolvimentista, os recursos e as aptidões, que se acham ocultos, dispersos ou mal empregados.

É essa descoberta que pode ser feita analisando a matriz de insumo-produto regionalizada para o Distrito Federal, e que faremos nos próximos itens. Antes, porém, é preciso chamar atenção para o fato de que os estímulos dados a alguns setores para induzir o crescimento de outros só conduzirão ao desenvolvimento de uma localidade ou região na medida em que, e tanto mais quanto, impedir o vazamento de renda. Ou seja, é preciso que se gere demanda de insumos de setores situados no DF ou na região próxima, ao invés de insumos importados de outras regiões, para garantir a geração de produção, emprego e renda locais e regionais. Em caso contrário, o impulso ao crescimento ocorrerá fora do Distrito Federal, deixando de gerar renda e emprego para sua população. Isso mostra que é preciso preocupar-se com o estímulo aos processos de produção locais, dos insumos e dos produtos a serem vendidos como bens finais e como insumos para outros setores, assim como é necessário buscar maximizar a entrada de renda a ser gasta no destino turístico.

Esse tipo de preocupação é particularmente importante ao se tratar de turismo, porque é freqüente a existência de casos em que o desenvolvimento do turismo trás impactos negativos para a população residente, ao ampliar o uso da infra- estrutura e dos bens e serviços disponíveis, sem contrabalançar isso com geração de renda e emprego. É o caso quando os pacotes de viagens são vendidos fora do destino turístico, contendo transporte e hospedagem, por exemplo, e quando a renda do turista não é gasta em produtos locais.

A esse respeito também Hirshman chamou atenção, ao dizer que é preciso buscar alternativas de crescimento endógenas, ou seja, que não dependam de estímulos externos sobre os quais se tem pouco controle, além de dizer que é preciso usar costumes e conhecimento locais para o que ele chamava de "aproveitamento de traços" no desenvolvimento das economias (Lepenies, 2009). Mais que isso, é preciso transformar tais traços característicos das 
produções no Distrito Federal em insumos e produtos a serem adquiridos pelos serviços que constituem o turismo e sua cadeia produtiva, assim como ampliar os gastos locais dos turistas.

Também para isso a matriz de insumo-produto é útil, ao permitir o cálculo dos efeitos de encadeamento e os impactos geradores de renda e emprego, permitindo uma visão mais precisa dos setores onde é possível obter ganhos mais amplos para as populações locais com o desenvolvimento do turismo. É possível planejar assim, de forma mais eficiente, os estímulos a serem dados pelas políticas públicas.

No que se refere ao desenvolvimento local ou regional a partir do turismo, é preciso dizer ainda que os economistas não têm posições consensuais a esse respeito. Como bem sintetizam Diniz e Crocco (2006), por um lado, temos políticas regionais chamadas de Topdown, que dominaram até os anos 1970, com ênfase na demanda e na correção das disparidades regionais. Elas enfatizavam os determinantes externos das desigualdades no processo de desenvolvimento, em função de um sistema hierarquizado e assimétrico de países e regiões. É o caso das teorias centro-periferia, de dependência e de efeitos cumulativos, que chamam atenção, com razão, para os fatores que tendem a manter a desigualdade entre as regiões, exigindo o papel do Estado para reduzir ou compensar tais desigualdades. Esse é, pois, um papel das políticas públicas.

Esse papel do Estado, ao invés do automatismo de mercado é também prescrito em teorias de desenvolvimento regionais como a do Big-push, de Rosenstein-Rodan (1969), a dos pólos de crescimento de Perroux (1955) e as que prescrevem prioridade industrial para eliminar ou reduzir diferenças estruturais responsáveis pelas diferenças (Myrdal, 1957; Hirschman, 1961), mecanismos de compensação para as regiões atrasadas, investimentos estratégicos do setor público e restrições à localização de atividades em determinadas regiões, para evitar a concentração.

Por outro lado, temos as teorias que passaram a predominar no período neoliberal, do tipo Botton-up, focando na produtividade endógena das economias e nos mecanismos de mercado para garantir o crescimento. A idéia, nesse caso, é a de capacitar as regiões para enfrentar a competição internacional a partir da mobilização de recursos específicos e habilidades próprias, ou seja, endógenos. 
Neste artigo, assumimos a posição de que os mecanismos de mercado são insuficientes, de fato, para garantir a redução de desigualdades, sejam desigualdades locais, setoriais ou regionais. Tendo em vista a importância da disponibilidade inicial de recursos e de tecnologia moderna, assim como a estrutura de pesquisa e de capacitação, que se distribuem de forma desigual seja local, regional ou setorialmente, o desenvolvimento econômico guiado pelo mercado tende a ampliar a concentração de capital e o desemprego, o mesmo ocorrendo com outras deficiências estruturais difíceis de serem sanadas por meio do mero desempenho do sistema de preços. Assim, é necessário um papel ativo do Estado e das políticas públicas, o que nos faz concordar com o primeiro grupo.

Isso, porém, não impede que se estimule a exploração de especificidades de cada local ou região e dos elementos endógenos responsáveis pelo crescimento. Isso é importante não apenas para facilitar, mas para tornar o crescimento sustentável ao longo do tempo, assim como para envolver nos ganhos econômicos a população local. Essa é a perspectiva que buscaremos explorar aqui ${ }^{4}$.

\section{A Matriz de Insumo-Produto e o Turismo no Distrito Federal}

Existem vários estudos usando a matriz de insumo-produto ${ }^{5}$ para analisar o potencial econômico do turismo em diferentes países. Wien (1989), analisando Vorarlber, na Áustria, destaca que a melhor maneira de analisar o impacto econômico do turismo é usando matrizes regionais de insumo-produto, e faz isso para calcular os efeitos do turismo na geração de valor adicionado, de receitas de impostos e na criação de empregos. Archer (1995) analisa o caso das Bermudas, comparando a contribuição relativa do turismo nas exportações, na geração de renda e emprego, e na renda do setor público, com a dos principais setores exportadores.

Mais recentemente, temos os trabalhos de Oosterhaven e Fan (2006) analisando o impacto do turismo internacional na economia chinesa, o de Surugiu, Frent e Surugiu (2009) sobre o turismo na Romênia, o de Blake (2008), avaliando o impacto do turismo sobre a distribuição de renda da África Oriental, o de Mitchell \& Ashley (2010) sobre turismo como um

\footnotetext{
${ }^{4}$ Segundo Diniz e Crocco, a síntese exógeno-endógeno tem sido tendência mais recente nos estudos de desenvolvimento regional.

${ }^{5}$ A matriz de insumo-produto foi desenvolvida inicialmente por Leontief (1951).
} 
instrumento para a redução da pobreza. Todos esses apresentam aplicações do instrumental de insumo-produto para análise do turismo.

Para o Brasil, o trabalho de Casimiro Filho $(2002)^{6}$ é referência no assunto. Depois dele o Centro de Excelência em Turismo (CET) da Universidade de Brasília calculou a matriz de insumo-produto e de contabilidade social com dados de 2002, conforme Arbache et.al. (2008), e vem atualizando e recalculando as matrizes para o Brasil bem como a matriz regionalizada usada neste artigo (Andrade, 2008; Takasago e Mollo, 2010, CET, 2010).

Neste item descreveremos alguns dos resultados da mencionada matriz regionalizada, com o objetivo de tirar algumas conclusões iniciais sobre a economia do turismo no Distrito Federal em comparação a economia do DF como um todo e as conclusões já tiradas em outros trabalhos sobre o turismo no Brasil.

De forma a separar dentre os serviços que servem a turistas e a residentes, apenas aqueles que sevem aos primeiros, que caracterizam o turismo propriamente dito, foi preciso, inicialmente, escolher um procedimento de cálculo. Uma estimativa precisa só pode ser obtida com dados da conta satélite de turismo, que ainda se acha em fase de elaboração pelo IBGE. O que temos hoje é o resultado de uma pesquisa do IPEA (2006) sobre emprego no setor turístico que permite obter alguns coeficientes de participação do turismo na utilização dos mencionados serviços. Foram esses os coeficientes usados aqui para o setor turismo.

O Gráfico 1 adiante mostra a participação de cada serviço no turismo, usando os mencionados coeficientes de emprego no turismo calculados para o DF pelo IPEA. Apenas no caso do setor de transporte rodoviário não utilizamos o mencionado coeficiente, porque a simples desagregação do setor de transportes permite a mensuração apenas dos serviços que são utilizados pelos turistas ${ }^{7}$.

Observa-se, pelo Gráfico 1, que o setor de transporte municipal rodoviário de passageiros tem a maior participação na formação do turismo, com 38\% do total, seguindo-se os setores de alimentação, de transporte aéreo de passageiros e de transporte rodoviário interestadual de

\footnotetext{
${ }^{6}$ Veja também Casimiro Filho e Guilhoto (2003).

${ }^{7}$ Os coeficientes encontrados pela pesquisa do IPEA (2006) para o emprego dedicado especificamente ao atendimento de turistas no DF foram: alojamento: 59,2\%; alimentação: 12,08\%; transporte: 52,82\%; auxiliares de transporte: 19,05\%; agências de viagens: 82,6\%; aluguel de transporte: 31,5\%; cultura e lazer: 15,88\%.
} 
passageiros, cada um com $8 \%$ do total. Ou seja, deveria ser grande o interesse em manter um transporte rodoviário eficiente, quando se quer desenvolver o turismo, não apenas para servir bem aos turistas e aos residentes, mas em virtude da sua participação no PIB produzido pelo turismo no Distrito Federal.

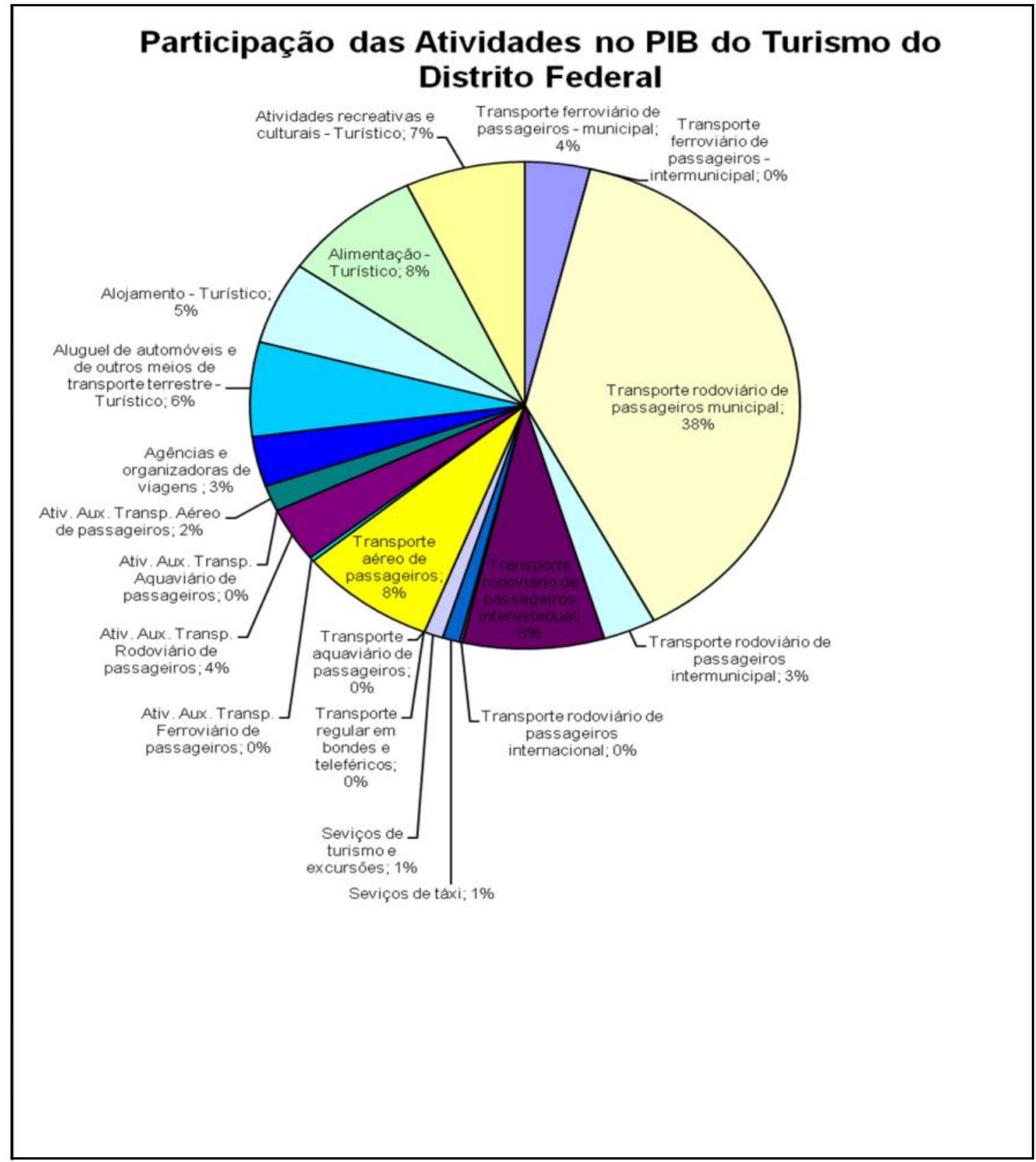

Fonte: dados da pesquisa.

Gráfico 1 - Composição do Turismo no DF 
O Quadro 1, por sua vez, é uma matriz de insumo-produto regionalizada, ou seja, separandose os dados do Distrito Federal daqueles calculados pelo IBGE para o Brasil. Ela é de 2004, últimos dados revisados disponíveis para regionalização, e acha-se reduzida, ou seja, a matriz originalmente construída contém 81 setores. Estes setores foram, como apresentado na Quadro 1, agregados em agricultura, indústria, serviços e turismo, de forma a termos uma idéia do significado da matriz.

A relação insumo-produto pode ser analisada na parte superior esquerda da quadro, que se acha sombreada. Ela contém os quatro setores nas linhas e nas colunas, divididos cada um em dois, o primeiro relativo ao Distrito Federal, e o segundo referente ao restante do Brasil. Ao ler cada coluna, pode-se observar os volumes de compras feitas pelos vários setores daqueles insumos necessários ao seu processo produtivo. Ao ler as linhas, por sua vez, consegue-se saber os volumes de vendas que cada setor faz de insumos para os outros.

A leitura das linhas permite ter idéia da importância estratégica de cada setor no fornecimento de insumos, viabilizando, com isso, as produções dos demais, enquanto as colunas indicam a importância deles demandando insumos dos outros. No primeiro caso, é possível perceber, por exemplo, quais as produções que precisam crescer quando se quer estimular algum setor específico, e no segundo caso, é possível verificar quais os setores que são importantes para estimular a produção dos demais, ao fornecer-lhes a demanda necessária. Isso indica quão importantes podem ser as informações da matriz para efeito de planejamento de políticas públicas, destacando, por um lado, onde existem pontos de estrangulamento a resolver e, por outro, quais os setores que prioritariamente devem ser estimulados quando o objetivo é estimular a produção de vários deles. Mas também o Quadro pode ser de utilidade para a iniciativa privada, ao permitir visualizar quais os setores que tendem a crescer, seja para atender à demanda de insumos, seja se aproveitando do excesso de produção de insumos em setores específicos. 
Quadro 1 - Matriz de Insumo-Produto - O Turismo e a Economia do Distrito Federal e o resto do Brasil - 2004 - R\$ milhões

\begin{tabular}{|c|c|c|c|c|c|c|c|c|c|c|c|}
\hline & \begin{tabular}{|l} 
Agrope- \\
cuária \\
DF \\
\end{tabular} & $\begin{array}{l}\text { Agropecu- } \\
\text { ária RB }\end{array}$ & $\begin{array}{l}\text { Indústria } \\
\text { DF }\end{array}$ & $\begin{array}{l}\text { Industria } \\
\text { RB } \\
\end{array}$ & $\begin{array}{l}\text { Serviço } \\
\text { DF }\end{array}$ & Serviço RB & $\begin{array}{l}\text { Turismo } \\
\text { DF } \\
\end{array}$ & $\begin{array}{l}\text { Turismo } \\
\text { RB }\end{array}$ & $\begin{array}{l}\text { Dem. } \\
\text { Intermed. }\end{array}$ & Dem. Total & $\begin{array}{l}\text { Valor Br. da } \\
\text { Produção }\end{array}$ \\
\hline Agropecuária DF & 49,05 & 14,09 & 218,78 & 22,37 & 17,56 & 0,02 & 1,24 & 0,01 & 323,11 & 261,53 & 584,64 \\
\hline Agropecuária RB & 22,67 & $18.088,87$ & 203,48 & $107.430,93$ & 168,55 & $2.895,12$ & 5,21 & 236,05 & $129.050,89$ & $73.496,47$ & $202.547,36$ \\
\hline Indústria DF & 105,94 & 51,03 & $1.144,38$ & 380,49 & $4.382,43$ & 9,40 & 76,68 & 1,31 & $6.151,65$ & $2.893,98$ & $9.045,63$ \\
\hline Indústria RB & 61,41 & $42.737,19$ & $1.725,41$ & $574.109,50$ & $6.178,88$ & $146.445,56$ & 476,59 & $15.674,81$ & $787.409,35$ & $783.478,02$ & $\mathbf{1 . 5 7 0 . 8 8 7 , 3 7}$ \\
\hline Serviço DF & 51,23 & 95,17 & 960,11 & $1.700,80$ & $23.804,80$ & 574,68 & 389,54 & 31,12 & $27.607,45$ & $71.954,96$ & $99.562,41$ \\
\hline Serviço RB & 0,08 & $13.020,62$ & 36,71 & $192.475,68$ & $1.993,99$ & $280.269,78$ & 24,91 & $11.873,99$ & $499.695,76$ & $973.126,84$ & $1.472 .822,61$ \\
\hline Turismo DF & 0,57 & 1,23 & 18,54 & 34,97 & 710,70 & 14,92 & 33,23 & 1,16 & 815,33 & $1.225,28$ & $2.040,61$ \\
\hline Turismo RB & 0,03 & 151,58 & 0,81 & $4.281,33$ & 78,80 & $10.983,67$ & 2,25 & 954,68 & $16.453,16$ & $54.984,16$ & $71.437,31$ \\
\hline Consumo Intermed. & 290,98 & $74.159,78$ & $4.308,22$ & $880.436,08$ & $37.335,70$ & $441.193,14$ & $1.009,65$ & $28.773,13$ & $1.467 .506,69$ & & \\
\hline $\begin{array}{l}\text { Cons.Intermed. + } \\
\text { Impostos + Import. } \\
\end{array}$ & 325,06 & $87.612,94$ & $4.797,93$ & $1.073 .364,07$ & $41.962,51$ & $519.704,11$ & $1.167,10$ & $35.047,29$ & & & \\
\hline Vl.Ad. PIB c.f & 257,27 & $114.203,73$ & $4.174,82$ & $485.628,18$ & $57.239,70$ & $944.820,30$ & 862,81 & $35.994,19$ & & & \\
\hline $\begin{array}{l}\text { Remunerações - } \\
\text { inclusive autônomos }\end{array}$ & 214,03 & $92.606,97$ & $1.757,65$ & $221.971,35$ & $43.795,03$ & $566.917,33$ & 586,53 & $24.093,83$ & & & \\
\hline $\begin{array}{l}\text { EOB (Empregador e } \\
\text { Capital) - Lucros }\end{array}$ & 43,24 & $21.596,76$ & $2.417,18$ & $263.656,82$ & $13.444,68$ & $377.902,97$ & 276,28 & $11.352,08$ & & & \\
\hline Vl.Ad. PIB c.f & 257,27 & $114.203,73$ & $4.174,82$ & $485.628,18$ & $\mathbf{5 7 . 2 3 9 , 7 0}$ & $944.820,30$ & 862,81 & $35.994,19$ & & & \\
\hline +Impostos -Subs. & 2,32 & 730,68 & 72,88 & $11.895,12$ & 360,20 & $9.609,26$ & 10,71 & 395,84 & & & \\
\hline Vl Ad PIB PB & 259,58 & $114.934,42$ & $4.247,70$ & $497.523,30$ & $\mathbf{5 7 . 5 9 9 , 9 0}$ & $\mathbf{9 5 4 . 4 2 9 , 5 6}$ & 873,52 & $36.390,02$ & & & \\
\hline Valor Br.Prod & 584,64 & 202.547,36 & $9.045,63$ & $1.570 .887,37$ & $99.562,41$ & \begin{tabular}{|l|}
$1.474 .133,67$ \\
\end{tabular} & $2.040,61$ & $71.437,31$ & & & \\
\hline
\end{tabular}

Fonte: dados da pesquisa 
De forma a melhor visualizar a posição do turismo no DF, antes de detalhar o potencial de cada setor na geração de produção, emprego e renda, o Quadro 2 adiante compara o setor com a economia do Distrito Federal como um todo quanto a diferentes variáveis. Observe-se, em primeiro lugar, que o turismo do DF contribui com $1,4 \%$ do $\mathrm{PIB}$, o que, comparado com o turismo no Brasil, que contribui com cerca de 2,3\%, mostra um grande espaço para o seu desenvolvimento na capital da República. Ao comparar essa contribuição do turismo para o PIB do DF, com a situação dos demais dados, é possível analisar outras características do turismo no Distrito Federal. Vemos, assim, que se destaca o papel das remunerações de autônomos no turismo. Enquanto o setor contribui com 1,4\% do PIB, as remunerações de autônomos ocupam participação maior no total destas remunerações no $\mathrm{DF}$, cerca de $5 \%$, indicando uma importância acentuada deste tipo de trabalho nas atividades turísticas. Esse é um traço encontrado não apenas no Distrito Federal, mas no turismo brasileiro como um todo (Mollo e Takasago, 2010). Destaca-se também a participação dos trabalhadores assalariados na composição da remuneração total do turismo nacional, o que não se verifica no caso do DF. Outra diferença com relação ao turismo no Brasil é a participação do capital, aproximadamente $1,7 \%$, que é maior do que a contribuição para o PIB no DF, ao contrário do que ocorre no Brasil onde essa participação é bem inferior ${ }^{8}$.

\footnotetext{
${ }^{8}$ A participação do PIB do turismo no PIB brasileiro é de aproximadamente 2,3\%, enquanto que a participação do capital do turismo no capital nacional é cerca de $1,7 \%$.
} 
Quadro 2 - As atividades características do turismo e a economia do Distrito Federal (R\$ milhões)

\begin{tabular}{|l|r|r|r|}
\hline Indicadores Macroeconômicos & \multicolumn{1}{|l|}{$\begin{array}{l}\text { A - Economia } \\
\text { do DF }\end{array}$} & $\begin{array}{l}\text { B- Turismo } \\
\text { DF }\end{array}$ & \multicolumn{1}{|c|}{ B/A (\%) } \\
\hline Valor Bruto da Produção & $111.233,29$ & $2.040,61$ & $1,83 \%$ \\
\hline PIB - Valor Adicionado c. f. & $62.534,60$ & 862,81 & $1,38 \%$ \\
\hline PIB - Valor Adicionado p. bas. & $62.980,70$ & 873,52 & $1,39 \%$ \\
\hline Demanda Total & $81.898,56$ & $1.508,58$ & $1,84 \%$ \\
\hline Salários de Trabalhadores & $43.245,99$ & 425,12 & $1,00 \%$ \\
\hline Remunerações de Autônomos & 3107,24 & 161,41 & $5,10 \%$ \\
\hline $\begin{array}{l}\text { Remunerações de trabalhadores e } \\
\text { autônomos }\end{array}$ & $46.353,23$ & 586,53 & $1,27 \%$ \\
\hline $\begin{array}{l}\text { Excedente op. Bruto ou Capital (sem } \\
\text { trabalhadores autônomos) }\end{array}$ & $16.181,37$ & 276,28 & $1,71 \%$ \\
\hline
\end{tabular}

Fonte: dados da pesquisa

Isso, porém, não significa que o setor é intensivo em capital. Ao contrário, quando mensuramos a participação das remunerações de trabalhadores assalariados e autônomos no PIB a custo de fatores do DF, como no Quadro 3, percebemos que eles têm uma participação de quase 68\%, contra uma participação do capital de $32 \%$, mostrando-se, portanto, um setor intensivo em trabalho.

Quadro 3 - Remunerações do Trabalho e do Capital (R\$ milhões)

\begin{tabular}{|l|l|l|}
\hline Remunerações & Turismo - DF & Participação no PIBcf \\
\hline Salários de Trabalhadores & 425,12 & $49,27 \%$ \\
\hline Trabalhadores Autônomos & 161,41 & $18,71 \%$ \\
\hline $\begin{array}{l}\text { Remunerações de trabalhadores incluindo } \\
\text { autônomos }\end{array}$ & 586,53 & $67,98 \%$ \\
\hline $\begin{array}{l}\text { Excedente op. Bruto ou Capital (sem trabalhadores } \\
\text { autônomos) }\end{array}$ & 276,28 & $32,02 \%$ \\
\hline
\end{tabular}

Fonte: dados da pesquisa 
De forma a melhor analisar o potencial de geração de produção, emprego e renda que o turismo no Distrito Federal tem, descreveremos no próximo item os efeitos de encadeamento do mesmo para trás e para frente e os potenciais geradores de produção, emprego e renda de cada setor constituinte do turismo.

\section{Os Efeitos de Encadeamento e o Potencial de Crescimento Econômico do Turismo no}

\section{Distrito Federal}

Conforme mencionado no item 1, quanto maiores os efeitos de encadeamento maior é o estímulo fornecido pelo crescimento de um setor para os demais, seja por meio de demanda aumentada de insumos, seja ampliando a oferta de insumos para as produções dos demais. Assim, os setores que mais conseguem difundir os estímulos dados à sua produção são aqueles que apresentam maiores coeficientes para trás e para frente. No caso do turismo no DF, os efeitos para trás, demandando insumos, são maiores do que os para frente. Isto é demonstrado no Quadro 4, que contém os efeitos para trás e frente. Os Gráficos 2 e 3 ilustram a comparação entre esses efeitos com o efeito médio observado entre os 81 setores que compõem a economia do DF.

Essa é uma conclusão muito comum nas análises sobre o turismo, como é observado por Oosterhaven e Fan (2006), referindo-se à China e mencionado também em trabalhos anteriores de Archer (1995), sobre Bermudas, e de Archer e Fletcher, (1996), sobre Seychelles. O mesmo se observa para a África Oriental, no trabalho Blake (2008). Esse tipo de observação decorre do fato do turismo ser um serviço ou um conjunto de serviços usados principalmente para consumo final, ao invés de usados nos processos produtivos das demais mercadorias e dos demais serviços. 
Quadro 4 - Efeitos de Encadeamentos para Trás e Frente

\begin{tabular}{|l|l|l|}
\hline Setores & Trás & Frente \\
\hline Transporte ferroviário de passageiros - municipal & 1,09 & 0,76 \\
\hline Transporte rodoviário de passageiros municipal & 0,94 & 0,82 \\
\hline Transporte rodoviário de passageiros intermunicipal & 0,91 & 0,77 \\
\hline Transporte rodoviário de passageiros interestadual & 0,90 & 0,77 \\
\hline Transporte rodoviário de passageiros internacional & 0,93 & 0,76 \\
\hline Serviços de táxi & 0,87 & 0,76 \\
\hline Serviços de turismo e excursões & 0,88 & 0,76 \\
\hline Transporte aéreo de passageiros & 1,03 & 0,80 \\
\hline Ativ. Aux. Transp. Ferroviário de passageiros & 0,89 & 0,77 \\
\hline Ativ. Aux. Transp. Rodoviário de passageiros & 0,86 & 0,81 \\
\hline Ativ. Aux. Transp. Aéreo de passageiros & 0,94 & 0,80 \\
\hline Agências e organizadoras de viagens & 1,03 & 0,79 \\
\hline Aluguel de automóveis e de outros meios de transporte terrestre & 0,79 & 0,78 \\
\hline Alojamento & 1,04 & 0,76 \\
\hline Alimentação & 1,10 & 0,79 \\
\hline Atividades recreativas e culturais & 0,93 & 0,76 \\
\hline Média da Economia do DF & $\mathbf{1 , 0 0}$ & $\mathbf{1 , 0 0}$ \\
\hline Font: dados da pesquisa & & \\
\hline
\end{tabular}

Fonte: dados da pesquisa

De forma a analisar o potencial de estímulo à produção, à geração de renda e de emprego de cada setor constituinte do turismo, foram estimados os efeitos geradores dessas variáveis e compararemos com os respectivos efeitos geradores médios da economia do Distrito Federal.

O Quadro 5, por exemplo, mostra o impacto que o aumento de uma unidade monetária de demanda final de cada setor tem sobre a produção de outros setores. A geração de produção, pode ser de forma direta, quando ocorre no próprio setor, ao responder, por exemplo, a um aumento de demanda, mas pode ocorrer também de forma indireta, ou seja, ao afetar outros setores que precisam crescer para atender à maior demanda dos serviços turísticos, e pode ser de forma induzida. Neste último caso, a produção da economia como um todo precisa 
aumentar para atender ao aumento de consumo que surge do aumento de renda e do emprego decorrentes dos aumentos de produção direta e indireta mencionados anteriormente.

Quadro 5 - Geradores de Produção

\begin{tabular}{|l|r|r|r|r|}
\hline Setores & \multicolumn{1}{|c|}{ Direto } & \multicolumn{1}{l|}{ Indireto } & \multicolumn{1}{l|}{ Induzido } & \multicolumn{1}{l|}{ Total } \\
\hline Transporte ferroviário de passageiros - municipal & 1 & 0,57 & 0,32 & 1,89 \\
\hline Transporte rodoviário de passageiros municipal & 1 & 0,3 & 0,22 & 1,51 \\
\hline Transporte rodoviário de passageiros intermunicipal & 1 & 0,25 & 0,21 & 1,46 \\
\hline Transporte rodoviário de passageiros interestadual & 1 & 0,25 & 0,2 & 1,45 \\
\hline Transporte rodoviário de passageiros internacional & 1 & 0,29 & 0,19 & 1,48 \\
\hline Serviços de táxi & 1 & 0,19 & 0,24 & 1,43 \\
\hline Serviços de turismo e excursões & 1 & 0,2 & 0,22 & 1,42 \\
\hline Transporte aéreo de passageiros & 1 & 0,46 & 0,18 & 1,64 \\
\hline Ativ. Aux. Transp. Ferroviário de passageiros & 1 & 0,22 & 0,28 & 1,51 \\
\hline Ativ. Aux. Transp. Rodoviário de passageiros & 1 & 0,17 & 0,3 & 1,47 \\
\hline Ativ. Aux. Transp. Aéreo de passageiros & 1 & 0,31 & 0,3 & 1,61 \\
\hline Agências e organizadoras de viagens & 1 & 0,48 & 0,26 & 1,73 \\
\hline $\begin{array}{l}\text { Aluguel de automóveis e de outros meios de transporte } \\
\text { terrestre }\end{array}$ & 1 & 0,06 & 0,03 & 1,09 \\
\hline Alojamento & 1 & 0,42 & 0,32 & 1,74 \\
\hline Alimentação & 1 & 0,49 & 0,23 & 1,72 \\
\hline Atividades recreativas e culturais & 1 & 0,31 & 0,32 & 1,63 \\
\hline Média da Economia do DF & $\mathbf{1}$ & $\mathbf{0 , 3 9}$ & $\mathbf{0 , 2}$ & $\mathbf{1 , 5 8}$ \\
\hline
\end{tabular}

Fonte: dados da pesquisa

Observe-se, a esse respeito, que alguns setores constituintes do turismo no DF destacam-se no estímulo à produção dos demais, porque os efeitos geradores de produção estão acima da média da economia do DF como um todo. É o que é possível verificar no Quadro 5 acima e no Gráfico 2, em que a linha indica a média e o valor do gerador, para cada setor do turismo, acha-se representado nas barras. Quando examinamos o Gráfico 2, vemos os efeitos totais de geração de produção, dado mais importante quando se trata de desenhar políticas públicas e estabelecer prioridades. Nele verificamos que os setores que mais contribuem para o aumento 
da produção dos demais são: transporte ferroviário de passageiros, alimentação, aluguel de automóveis e outros meios de transporte terrestre e atividades recreativas e culturais. Observase a esse respeito, por exemplo, que para atender a um aumento de $\mathrm{R} \$ 1,00$ de demanda final no setor de transporte ferroviário de passageiros, gera-se $\mathrm{R} \$ 1,89$ de produção total no conjunto da economia do Distrito Federal. No caso do setor de alojamento esse efeito é de $\mathrm{R} \$ 1,74$ de aumento da produção do DF por cada aumento de $\mathrm{R} \$ 1,00$ em sua demanda final, e no caso do setor de alimentação, para cada aumento de sua demanda final em $\mathrm{R} \$ 1,00$ a produção do DF aumenta $\mathrm{R} \$ 1,72$.

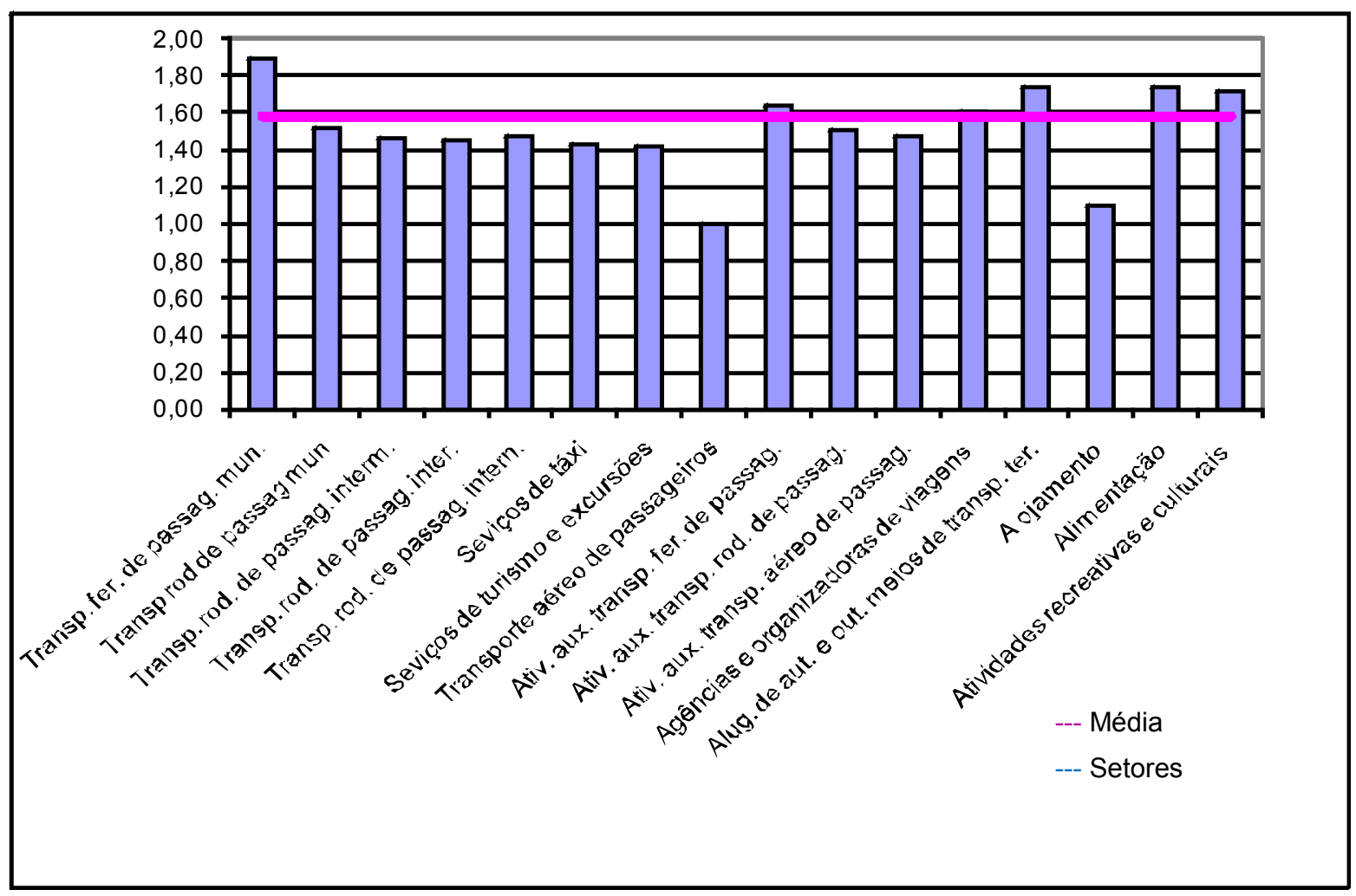

Fonte: dados da pesquisa

Gráfico 2 - Geradores de Produção- Efeito Total 
Quadro 6 - Geradores de Emprego

\begin{tabular}{|l|r|r|r|r|}
\hline Setores & Direto & Indireto & Induzido & Total \\
\hline Transporte ferroviário de passageiros - municipal & 12 & 9 & 9 & 30 \\
\hline Transporte rodoviário de passageiros municipal & 49 & 8 & 6 & 63 \\
\hline $\begin{array}{l}\text { Transporte rodoviário de passageiros } \\
\text { intermunicipal }\end{array}$ & 24 & 7 & & \\
\hline Transporte rodoviário de passageiros interestadual & 39 & 7 & 6 & 37 \\
\hline $\begin{array}{l}\text { Transporte rodoviário de passageiros } \\
\text { internacional }\end{array}$ & 33 & 8 & 5 & 46 \\
\hline Serviços de táxi & 51 & 5 & 7 & 63 \\
\hline Serviços de turismo e excursões & 29 & 5 & 6 & 41 \\
\hline Transporte aéreo de passageiros & 2 & 13 & 5 & 20 \\
\hline Ativ. Aux. Transp. Ferroviário de passageiros & 8 & 6 & 8 & 22 \\
\hline Ativ. Aux. Transp. Rodoviário de passageiros & 8 & 4 & 8 & 20 \\
\hline Ativ. Aux. Transp. Aéreo de passageiros & 8 & 7 & 8 & 23 \\
\hline Agências e organizadoras de viagens & 38 & 10 & 7 & 56 \\
\hline $\begin{array}{l}\text { Aluguel de automóveis e de outros meios de } \\
\text { transporte terrestre }\end{array}$ & 17 & 1 & 1 & 19 \\
\hline Alojamento & 61 & 11 & 9 & 81 \\
\hline Alimentação & 69 & 14 & 6 & 88 \\
\hline Atividades recreativas e culturais & 53 & 7 & 9 & 69 \\
\hline Média da Economia do DF & $\mathbf{2 2}$ & $\mathbf{9}$ & $\mathbf{5}$ & $\mathbf{3 6}$ \\
\hline
\end{tabular}

Fonte: dados da pesquisa

Para cada aumento de R \$1milhão na demanda final de cada setor analisado, o Quadro 6 informa o número total de empregos gerados na economia do DF. Assim, vemos que o setor de alimentação gera 88 empregos, o de alojamento 81 e o de atividades recreativas e culturais gera 69, para cada aumento de $\mathrm{R} \$ 1$ milhão na demanda final em cada um destes setores, sendo eles os que mais geram empregos. Esses são os empregos totais quando somados os empregos diretos - gerados no próprio setor - os indiretos, quer dizer, os gerados em outros setores para atender ao crescimento do setor em questão e os induzidos, ou seja, criados em terceiros setores para responder à demanda de consumo aumentada com os aumentos de emprego diretos e indiretos. 
O Gráfico 3 consolida a informação sobre empregos gerados, ilustrando os efeitos totais de geração de empregos. Vemos nele que se destacam os setores de alimentação, alojamento, atividades recreativas e culturais e transporte rodoviário municipal de passageiros, não apenas em relação aos setores constituintes do turismo, mas em relação ao poder gerador de emprego da economia do DF como um todo. Observa-se que esses setores possuem geradores bem acima da média observada na economia. Essa afirmação pode ser verificado pela reta que representa essa média, esboçada no Gráfico 3.

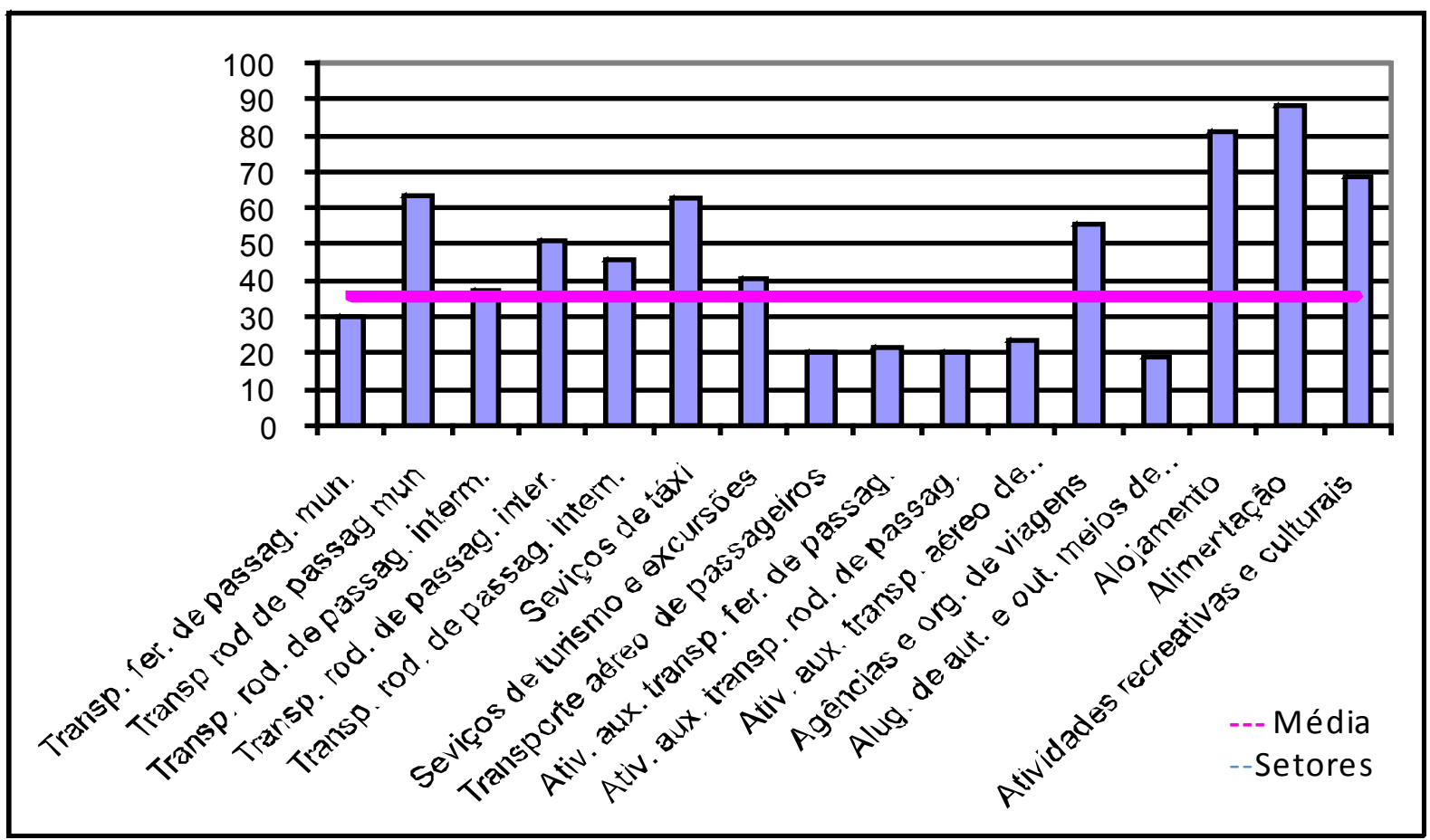

Fonte: dados da pesquisa

Gráfico 3 - Geradores de Empregos Totais

Quanto ao potencial de geração de renda de cada setor constituinte do turismo, o Quadro 7 mostra o impacto na renda do Distrito Federal quando aumenta a demanda final de cada setor em uma unidade monetária. Veja, por exemplo, o setor de atividades auxiliares do transporte rodoviário de passageiros, que apresenta maior gerador de renda. Para cada aumento $\mathrm{R} \$ 1,00$ na demanda final desse setor, a renda da economia do DF é aumentada em 
$\mathrm{R} \$ 1,045$. Esses dados são o de geração total de renda, somadas as rendas geradas diretamente, indiretamente e de forma induzida.

Quadro 7 - Geradores de Renda

\begin{tabular}{|l|r|r|r|r|}
\hline Setores & \multicolumn{1}{|c|}{ Direto } & Indireto & Induzido & \multicolumn{1}{l|}{ Total } \\
\hline Transporte ferroviário de passageiros - municipal & 0,43 & 0,32 & 0,18 & 0,93 \\
\hline Transporte rodoviário de passageiros municipal & 0,38 & 0,16 & 0,12 & 0,67 \\
\hline $\begin{array}{l}\text { Transporte rodoviário de passageiros } \\
\text { intermunicipal }\end{array}$ & 0,52 & 0,14 & 0,12 & 0,78 \\
\hline Transporte rodoviário de passageiros interestadual & 0,48 & 0,13 & 0,12 & 0,73 \\
\hline Transporte rodoviário de passageiros internacional & 0,41 & 0,16 & 0,11 & 0,67 \\
\hline Serviços de táxi & 0,56 & 0,1 & 0,14 & 0,8 \\
\hline Serviços de turismo e excursões & 0,58 & 0,11 & 0,13 & 0,82 \\
\hline Transporte aéreo de passageiros & 0,24 & 0,26 & 0,1 & 0,6 \\
\hline Ativ. Aux. Transp. Ferroviário de passageiros & 0,61 & 0,13 & 0,16 & 0,9 \\
\hline Ativ. Aux. Transp. Rodoviário de passageiros & 0,78 & 0,1 & 0,17 & 1,05 \\
\hline Ativ. Aux. Transp. Aéreo de passageiros & 0,63 & 0,18 & 0,17 & 0,98 \\
\hline Agências e organizadoras de viagens & 0,42 & 0,26 & 0,15 & 0,83 \\
\hline $\begin{array}{l}\text { Aluguel de automóveis e de outros meios de } \\
\text { transporte terrestre }\end{array}$ & 0,89 & 0,03 & 0,02 & 0,94 \\
\hline Alojamento & 0,56 & 0,18 & 0,18 & 0,92 \\
\hline Alimentação & 0,43 & 0,21 & 0,13 & 0,77 \\
\hline Atividades recreativas e culturais & 0,65 & 0,16 & 0,18 & 0,99 \\
\hline Média da Economia do DF & $\mathbf{0 , 4 3}$ & $\mathbf{0 , 1 9}$ & $\mathbf{0 , 1 1}$ & $\mathbf{0 , 7 3}$ \\
\hline
\end{tabular}

Fonte: dados da pesquisa

O Gráfico 4 mostra esse impacto total de aumento de renda, ou seja, a somatória dos efeitos diretos (no próprio setor), indiretos (em outros setores) e induzidos (em terceiros setores para atender à demanda de consumo aumentada com os aumentos diretos e indiretos de renda e emprego), de aumentos de renda que surgem quando o setor cresce para atender a aumento de R1,00 na sua demanda.

Observe-se que vários são os setores que se colocam acima da média da economia do Distrito Federal como um todo no que se refere à geração de renda, o que dá razão ao interesse em 
estimular o turismo local. São eles os setores de atividades auxiliares do transporte rodoviário de passageiros, atividades recreativas e culturais, atividades auxiliares do transporte aéreo de passageiros, aluguel de automóveis e outros, alojamento, transporte ferroviário de passageiros, atividades auxiliares do transporte aéreo de passageiros, agências de viagens, alimentação e transporte rodoviário intermunicipal de passageiros.

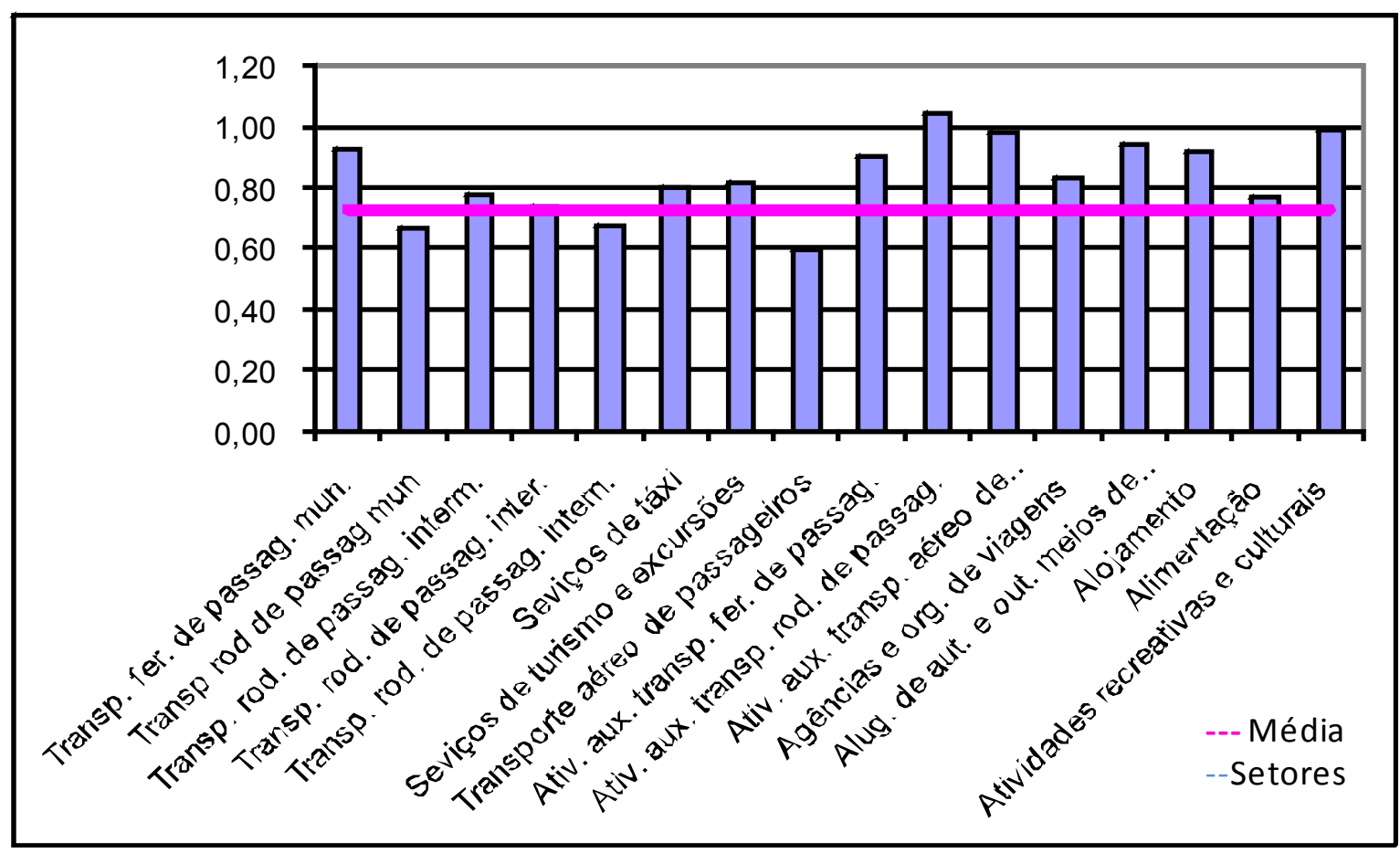

Fonte: dados da pesquisa

\section{Gráfico 4 - Geradores de Renda Total}

\section{Considerações Finais}

Vimos ao longo deste artigo que o crescimento em um setor específico da economia tende a se espalhar pelo restante dela por meio dos estímulos que fornece por meio da demanda de insumos e do aumento do fornecimento destes. Assim, para estimular uma economia nem sempre é necessário injetar recursos em todos os setores, mas apenas em alguns, o que é uma conclusão importante quando os recursos, em particular aqueles destinados a políticas 
públicas, são escassos. A pulverização desses recursos escassos, por sua vez, pode levar a ineficiências, porque há gastos que exigem um nível mínimo elevado, e são fundamentais para o crescimento específico de um setor ou atividade. Assim, é fundamental escolher bem os setores a serem estimulados, buscando com isso potencializar os ganhos da economia como um todo.

A estratégia de crescimento desequilibrado proposta por Hirshman é, a esse respeito, muito útil, porque mostra justamente o porquê do crescimento maior proporcionado por alguns setores do que por outros. Essa estratégia pode ser conduzida com mais precisão a partir dos dados fornecidos pela matriz de insumo-produto de Leontief, que permite calcular os efeitos de encadeamento para trás e para frente, destacando os setores em que esses efeitos são maiores, o que permitirá destacar aqueles que devem ser priorizados. Em particular na análise do turismo esses dados são importantes, porque o turismo, do ponto de vista econômico nada mais é do que um conjunto de setores cujos produtos são demandados pelos turistas.

A análise feita aqui da matriz de insumo-produto do Distrito Federal, assim como o cálculo dos efeitos de encadeamento para trás e para frente e dos efeitos geradores de produção, renda e emprego, indicam que o turismo tem bom potencial de geração de empregos, mas principalmente de renda, no DF, quando comparado com o conjunto de setores da economia do DF, ou com a média entre esses setores. Isso indica que o uso de políticas públicas direcionadas ao setor pode ter bons efeitos sobre o crescimento da economia como um todo.

Entre os setores que mais geram produção, destacam-se, na ordem, os setores abaixo:

$1^{\mathrm{o}}$ Transporte ferroviário municipal de passageiros

$2^{\circ}$ Alojamento

$3^{\circ}$ Agências e organizadoras de viagens

$4^{\mathrm{o}}$ Alimentação

$5^{\circ}$ Transporte aéreo de passageiros

$6^{\mathrm{o}}$ Atividades recreativas e culturais 
No que se refere à geração de empregos, os principais setores geradores dentro do turismo são os ordenados abaixo:

$1^{\mathrm{o}}$ Alimentação

$2^{\circ}$ Alojamento

$3^{\circ}$ Atividades recreativas e culturais

$4^{\mathrm{o}}$ Transporte rodoviário municipal de passageiros e Serviços de Taxi

$5^{\circ}$ Agências e organizadoras de viagens

Quanto à geração de renda, destacam-se os setores abaixo:

$1^{\mathrm{o}}$ Atividades Auxiliares do Transporte Rodoviário de passageiros

$2^{\circ}$ Atividades recreativas e culturais

$3^{\circ}$ Atividades Auxiliares do Transporte Aéreo de passageiros

$4^{\mathrm{o}}$ Aluguel de automóveis e de outros meios de transporte terrestre

$5^{\circ}$ Transporte ferroviário municipal de passageiros

$6^{\circ}$ Alojamento

Observe-se que os setores de alimentação, alojamento e atividades recreativas e culturais encontram-se entre os primeiros lugares tanto na geração de produção quanto como geradores de emprego e renda, indicando, nesse sentido, que deveriam ser priorizados com estímulos de políticas públicas.

Além disso, observe-se que os setores de agências e organizadores de turismo e de transporte ferroviário municipal de passageiros aparecem como principais em dois dos três potenciais analisados, colocando-se, nesse sentido, em segunda prioridade. As agências de viagem são bons geradores de produção e de emprego, e o transporte ferroviário de passageiros, onde se situa o metrô, é bom gerador de produção e de renda.

Finalmente, o setor de transporte municipal de passageiros vem sendo motivo de sérias e freqüentes queixas dos residentes, por sua insuficiência e má qualidade, n Distrito Federal. Os 
indicadores aqui analisados permitem perceber que a solução desses problemas, com investimentos no setor permite, não apenas que o desenvolvimento beneficie tanto a turistas quanto a residentes, tanto no que se refere à qualidade do serviço prestado como no que tange à geração de empregos.

O tipo de conclusão tirado aqui permite perceber o potencial que o instrumental de insumoproduto tem para orientar as políticas públicas no sentido garantir análises mais eficientes e resultados mais adequados. É, nesse sentido, uma ferramenta importante para nortear o crescimento das economias.

\section{Referências}

ANDRADE, J. et. AL. A Economia do Turismo no Brasil, Brasília: SENAC, 2008.

ARCHER, B. \& FLETCHER, J. E. The economic impact of tourism in the Seychelles. Annals of Tourism Research, 23: 32-47, 1996.

ARCHER, B. Importance of Tourism for economy of Bermuda. Annals of Tourism Research, Vol. 22(4), pp 918-930, 1995.

BLAKE, A. Tourism and Income Distribution in East Africa, International Journal of Tourism Research, 10, 511-524, 2008.

BLAKE, A.; ARBACHE, J., SINCLAIR, T. E TELES, V. Tourism and Poverty in Brazil, Annals of Tourism Research, Vol. 35, No. 1, pp. 107-126, 2008.

CASIMIRO FILHO, F. Contribuições do Turismo à Economia Brasileira, Tese de Doutorado, USP, 2002.

CASIMIRO FILHO, F. e GUILHOTO, J.J.M. Matriz de Insumo-Produto para a Economia Turística Brasileira: Construção e Análise das Relações Intersetoriais. Análise Econômica. Porto Alegre: FCE UFRGS. Ano 21, N. 40, Set, pp.227-263, 2003.

CET- Centro de Excelência em Turismo. Impacto do Turismo na Economia do Distrito Federal, Brasília: Editora SENAC, 2010.

DINIZ, C. C. E CROCCO, M. A. Introdução - Bases teóricas e instrumentais da economia regional urbana e sua aplicabilidade ao Brasil: uma breve reflexão. Dinz e Crocco (Org.), Economia Regional e Urbana - Contribuições Recentes, Belo Horizonte: Editora UFMG, 2006.

HIRSCHMAN, A. Economic Policy in Underdeveloped Countries. Economic Development and Cultural Change 5, no. 4 ,July, 1957.

. A estratégia do desenvolvimento econômico. Rio de Janeiro: Fundo de Cultura, 1961.

. Linkages, Eatwell, J. Milgate, M. e Newman, P. (eds.). The New Palgrave Economic

Development, Nova York: Norton, 1989. 
IPEA. Emprego no Turismo. 2006. Disponível em: <http://www.ipea.gov.br>.

LEONTIEF, W. The Structure of the American Economy. Second Edition. New York: Oxford University Press, 1951.

LEPENIES, P. H. Possibilismo: Vida e Obra de Albert O. Hirshman, Novos Estudos, 83, março, 2009.

MYRDAL, G. Economic theory and underdeveloped regions. New York: Harper Rose Publishers, 1957.

PERROUX, F. Note sur la notion de pole de croissance. Economie Apliquée, t. VIII, 1955.

OOSTERHAVEN, J. \& FAN T. Impact of International Tourism on the Chinese Economy. International Journal of Tourism Research, 8, 347-354, 2006.

ROSENSTEIN-RODAN, P. N.Problemas da industrialização da Europa Oriental e Sul Oriental. Agarwala, A. N. e Singh, S. P. A economia do subdesenvolvimento. Rio de Janeiro: Forense, 1969.

SOUZA, N. DE J. Desenvolvimento Econômico, São Paulo: Atlas, 2009.

SURUGIU, C. FRENT, C. \& SURUGIU, M. Tourism and its Impact upon the Romanian Economy: na input-output approach. Stiinte Economice, tomul LVI, 2009.

TAKASAGO, M. E MOLLO, M. L. R. A matriz de insumo-produto e a importância econômica do turismo no Brasil, Turismo \& Desenvolvimento, Aveiro, Vol. 13/14, 2010.

WIEN, E. S., The economic impacto of travel and tourism in mountain área: the case of Voralberg (Austria). Revue de Tourism, n.2, 1989, pp 25-29.

\section{Recebido em: 18/01/2011 (1 ${ }^{\text {a }}$ versão) 07/06/2011 ( $2^{\mathrm{a}}$ versão)}

Aprovado em: 14/06/2011 